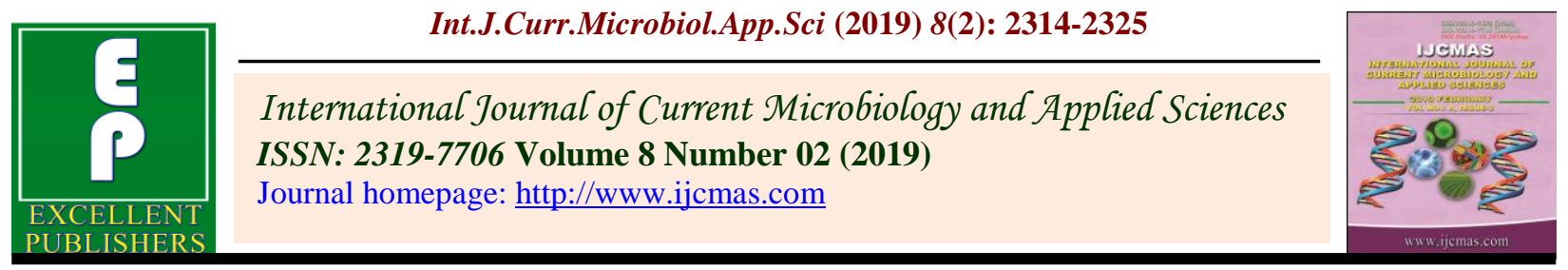

Original Research Article

https://doi.org/10.20546/ijcmas.2019.802.270

\title{
EST-SSR based Genetic Divergence and Prediction of Heterotic Combinations of Hybrid Parents in Pigeonpea
}

\author{
B.R. Raghu ${ }^{1}$, R.S. Raje $^{2}$, N.K. Singh ${ }^{3}$, K.B. Saxena ${ }^{4}$, D.A. Chauhan ${ }^{5}$, \\ S.A. Acharya ${ }^{6}$, A.N. Patil ${ }^{7}$, J.B. Patil ${ }^{6}$, K.B. Wanzari ${ }^{7}$ and D. Khare ${ }^{8}$ \\ ${ }^{1}$ ICAR-Vivekananda Parvatiya Krishi Anusandhan Sansthan, Almora, Uttarakhand, 263 601, India \\ ${ }^{2}$ Division of Genetics, ICAR-Indian Agricultural Research Institute, N. Delhi, India \\ ${ }^{3}$ ICAR-National Research Center on Plant Biotechnology, N. Delhi, India \\ ${ }^{4}$ Principal scientist (ICRISAT, Retd.), NMC housing complex, Al Ain, Abu Dhabi, UAE \\ ${ }^{5}$ Navsari Agricultural University, Navsari (Gujarat), India \\ ${ }^{6}$ SDAU, Sardakrishinagar, Dantiwada, Palanpur, Banaskantha (Gujarat), India \\ ${ }^{7} P D K V V$, Akola, Maharastra, India \\ ${ }^{8} \mathrm{JNKVV}$, Jabalpur, India \\ *Corresponding author
}

\section{A B S T R A C T}

Keywords

Cytoplasmicgenetic-malesterility, Geneticdiversity, Hybridbreeding, Microsatellitemarkers, Pigeonpea

Article Info

Accepted:

18 January 2019

Available Online:

10 February 2019

\begin{abstract}
Cytoplasmic-genic male sterile based $\mathrm{F}_{1}$ hybrid is a revolutionary approach to break yield stagnation in pigeonpea. Hybrid vigor is positively correlated to genetic distance and allelic divergence of the parents. This study estimated genetic divergence of 8 ' $A$ ' lines, 2 ' $B$ ' lines and 19 ' $R$ ' lines of $A_{2}$ and $A_{4}$ cytoplasmic sources, and predicted best parental combinations using molecular markers. Among 390 EST-SSR markers screened, only 60 markers found polymorphic indicating very low degree of polymorphism (15.4\%). Average allelic count was 2.26 with a range of 2-4 per loci. Mean PIC was 0.358 with a range of 0.5885 (ASSR236) and 0.1780 (ASSR9). Cluster and factorial analyses were performed based on marker dissimilarity matrix. The best parental combinations identified from the present study were, ICPA2047 X ICPR4013; ICPA2043 X ICPR4013 for A 4 cytoplasm, and GT290A X GTR9, GT33A X GTR9, MS01A X GTR 9, MS10A X GTR9 for $A_{2}$ cytoplasm in pigeonpea.
\end{abstract}

\section{Introduction}

Pigeonpea (Cajanus cajan (L.) Millsp.) is a versatile legume crop widely cultivated in semi-arid regions of Southeast Asia, Africa and Central America (FAOSTAT 2014). It is an important crop containing about $20-30 \%$ protein, contributing hugely to nutritional as well as economical security to small and marginal farmers. India stands first in both area and production of pigeon pea (FAOSTAT 2016). Its productivity is halted to less than 1 Tonn/hectare since last six decades. Initially efforts were made to improve productivity through pure line selection and recombination breeding. This was unsuccessful because of insignificant genetic gain due to narrow genetic base among cultivated pigeonpea (Kassa et al., 2012). Moreover, many breeders ignored the 
fact of $25-35 \%$ of heterosis and also cross pollination up to $70 \%$ by insect vectors, and thus handled it as self pollinated crop (Saxena et al., 1990, Saxena et al., 1992). As results, the focus was shifted towards exploitation of heterosis for higher productivity through development of $F_{1}$ hybrids.

Initially, genetic male sterile (GMS) based hybrids were developed, however, they failed to commercialize due to cumbersome nature of hybrid seed production (Dalvi et al., 2010). Subsequently, identification of stable cytoplasmic male sterile sources and suitable male fertility restorers, resulted into development of world's first cytoplasmicgenic male sterile (CGMS) based $\mathrm{F}_{1}$ hybrid in pigenpea, which was commercially feasible and high yielding (Saxena et al., 2013). Further identification of number of CMS sources out of cultivated gene pool and their successful transfer into cultivated background, has provided much needed impetus for hybrid breeding programmes in pigeonpea (Ariyanayagam et al., 1995, Wanjari et al., 1999, Saxena and Kumar, 2003, Mallikarjuna and Saxena, 2005, Saxena et al., 2005, Mallikarjuna et al., 2006, Saxena et al., 2010a, Saxena, 2013).

The CGMS based hybrid development is a three line breeding programme, which involves cytoplasmic male sterile line (CMS or ' $A$ ' line) as a female parent, cytoplasmic male sterile maintainer line (' $\mathrm{B}$ ' line) and male fertility restoration line (' $R$ ' line) as a male parent. However, genetic distance and allelic divergence between ' $A$ ' and ' $R$ ' lines will determine the hybrid vigor and performance of hybrids. Although, in pigeonpea, an extensive morphological diversity was observed within Cajanus genus as whole and cultivated species in particular, however, diversity analysis by molecular markers revealed low polymorphism in cultivated species than wild species (Odeny et al., 2007, Saxena et al., 2010b). This created assumption of abundance of genetic diversity within the cultivated species. Thus, selection of diverse parental combination only based on morphological diversity may sometimes mislead the breeders. However, a successful prediction of heterosis by molecular diversity studies was reported in other crop species such as rice (Zhang et al., 1994), maize (Lanza et al., 1997, Barbosa et al., 2003) and sorghum (Jordan et al., 2003). In pigeonpea, application of SSR markers in diversity analyses of germplasm, varieties, hybrid parental lines ('A', 'B' \& 'R' lines) and hybrid purity test was reported (Saxena et al., 2010c, Sheikh et al., 2014, Njung'e et al., 2016). Thus, present study was initiated to assess molecular diversity of CGMS systems of $C$. scarabaeoides $\left(\mathrm{A}_{2}\right)$ and $C$. cajanifolius $\left(\mathrm{A}_{4}\right)$ cytoplasmic sources and their heterotic combinations in pigeonpea.

\section{Materials and Methods}

\section{Plant materials}

The experimental materials consisted of 8 male sterile lines (' $\mathrm{A}$ ' lines), 2 male sterility maintainer lines (' $\mathrm{B}$ ' lines) and 19 male fertility restorers (' $R$ ' lines) derived from $A_{2}$ and $\mathrm{A}_{4}$ cytoplasmic sources (Table 1 ). These genotypes are extensively used as parental lines in the hybrid breeding programme at IARI, New Delhi, India.

\section{Genic-SSR markers}

In total, 390 Simple Sequence Repeat (SSR) primers designed from Expressed Sequence Taq (EST) of pigeonpea varieties Asha and UPAS120 were used (Datta et al., 2011).

\section{Isolation of genomic DNA}

Leaves samples were collected from one month old plants and stored at $-80^{\circ} \mathrm{C}$ in aluminum foils. Genomic DNA was isolated by using CTAB method as procedure 
described by Murray and Thompson (1980) and additional, $1 \%$ polyvinylpyrrolidone and $0.2 \%$ 2-mercaptoethanol were added in the extraction buffer. After the purification was over, the isolated genomic DNA was checked by electrophoresis on $0.8 \%$ agarose gel for quality and quantity. The quantification was also done by UV spectrophotometer at 260 nm.

\section{PCR amplification and Gel electrophoresis}

Each PCR reaction was prepared by: $1.5 \mu \mathrm{l}$ of $10 \times$ buffer, $0.20 \mu \mathrm{l}$ of $10 \mathrm{mM}$ dNTPs, $1.5 \mu \mathrm{l}$ each of forward and reverse primers (10pmol), $2.5 \mu 1$ of template genomic DNA (30ng/ $\mu \mathrm{l}), 0.15 \mu \mathrm{L}$ of Taq DNA polymerase $(5 \mathrm{U} / \mu \mathrm{l})$ (Vivantis Technologies) in a final reaction volume was made to $15 \mu$ l. The PCR reaction profile for amplification DNA was followed: pre-denaturation at $94^{\circ} \mathrm{C}$ for $5 \mathrm{~min}$. followed by 35 cycles of $94^{\circ} \mathrm{C}$ for $1 \mathrm{~min} ., 55^{\circ} \mathrm{C}$ for $1 \mathrm{~min} ., 72^{\circ} \mathrm{C}$ for $1 \mathrm{~min}$. and finally, $72^{\circ} \mathrm{C}$ for an extension of $7 \mathrm{~min}$. The PCR reactions were performed using PTC225 gradient cycler (MJ Research).

The electrophoresis was done to separate the amplified PCR products on high resolution agarose gels. To prepare high resolution agarose gels, 4\% Metaphor agarose have been used and slab gels (containing $0.1 \mu \mathrm{g} / \mathrm{ml}$ ethidium bromide) were prepared in $1 \mathrm{X}$ TBE buffer. The electrophoresis was done at $130 \mathrm{~V}$ for $3 \mathrm{~h}$ in TBE buffer. The gels were stained in ethidium bromide $(1 \mu \mathrm{g} / \mathrm{ml})$ solution for 20 minute. After electrophoresis, PCR amplified products were visualized and photographed on a UV transilluminator (Alpha innotech Corporation, USA) for analysis.

\section{Statistical analysis}

The markers profiles on resolution agarose gels were scored manually. Thus, allelic data obtained was used to prepare a dissimilarity matrix and to construct a two dimensional
(2D) plot using the factorial analysis method with DARWIN V5.0.128 software (Perrier et al., 2003). Genetic distance matrix was subjected to cluster analysis by UPGMA, to generate dendrogram using NTSYS-PC (Rohlf, 2000). Based on number of detectable alleles per marker and the distribution of their frequency, the value of a marker for detecting polymorphism within a given germplasm was determined. This value is known as the polymorphic information content (PIC). In the present study, the PIC value of markers was calculated using the following formula (Anderson and Lubberstedt 2003).

$$
P I C=1-\sum_{i=1}^{k} P_{i}^{2}
$$

Where $k$ is the total number of alleles detected for a given marker locus and $P i$ is the frequency of the $i^{\text {th }}$ allele in the lines analyzed.

\section{Results and Discussion}

Out of 390 EST-SSR markers screened, only 60 markers showed polymorphism in 29 test genotypes (Table 2). These polymorphic markers amplified a total of 136 alleles, with an average of 2.26 alleles per marker (Table 2). Majority of the markers (46) amplified two alleles, while a maximum of four alleles were amplified by two markers (ASSR17 and ARRS108). The PIC values calculated for these 60 polymorphic markers were in the range of 0.1780 (ASSR9) and 0.5885 (ASSR236) with an average of 0.3587 per marker (Table 2). The pattern of polymorphic profile produced by EST-SSR among pigeonpea genotypes was exemplified by two SSR markers, namely ASSR229 and ASSR236 in Figure 1. Overall polymorphism among test genotypes was $15.3 \%$, indicating a very low level of diversity among ' $A$ ' ' $B$ ' and ' $R$ ' lines. The present results were in agreement with earlier SSR-marker based 
diversity studies among $\mathrm{A}, \mathrm{B}$ and $\mathrm{R}$ lines of $A_{1}, \quad A_{2}$ and $A_{4}$ cytoplasmic sources in pigeonpea (Saxena et al., 2010c, Petchiammal et al., 2015). Besides, other SSR marker based diversity studies also indicated low polymorphism in different cultivated germplasm of pigeonpea (Burns et al., 2001; Odeny et al., 2007; Saxena et al., 2010b,d). In addition to SSR Markers, the narrow genetic base within cultivated pigeonpea was also evident from analyses based on other DNA marker systems such as RAPD(Ratnaparkhe et al., 1995), RFLP (Nadimpalli et al., 1993), AFLP (Panguluri et al., 2006), DArT (Yang et al., 2006), ISR (Kudapa et al., 2012), and SNP (Kassa et al., 2012).

Bohra et al., (2017) gave an overview of SSR-based diversity analyses in pigeonpea. In which, the average number of alleles per polymorphic SSR markers ranged 2.7 to 6.25 from different diversity studies, and the average PIC count was in the range of 0.3 to 0.63 . Though allelic count in the current study (2.26) was lower than earlier reports, but average PIC (0.3587) was in line with previous studies. The reason for low polymorphism and less allelic diversity may be the high selection pressure operated on pigeonpea genome for selection of genotypes from narrow germplasm for morphological traits and thus, pigeonpea genome is highly conserved. Thus, the future breeding strategies in pigeonpea must aim at introgression of favorable alleles from landraces and wild relatives to broaden the genetic base in order to maximize selection gain (Kassa et al., 2012).

Out of 60 polymorphic markers, 56 in ' $A$ ' lines and 59 in ' $R$ ' lines were polymorphic (Table 2). Earlier, Saxena et al., (2010c) also reported similar kind of a low diversity in 'A' lines. Whereas, Souframanien et al., (2003) reported contrasting results of higher diversity in ' $A$ ' lines. However, it is important to note that, 'A' lines in the study of Souframanien et al., (2003) were derived from $C$. sericeus $\left(\mathrm{A}_{1}\right)$ and $C$. scarabaeoides $\left(\mathrm{A}_{2}\right)$, but in the study of Saxena et al., (2010a), the 'A' lines were derived from $C$. cajanifolius $\left(\mathrm{A}_{4}\right)$. In current study, 'A' lines are derived from $C$. scarabaeoides (6) and C. cajanifolius (2). Thus, source of male sterile cytoplasm has no relevance in determining genetic divergence of ' $A$ ' lines. This was evident by observing comparatively higher level of genetic diversity in ' $\mathrm{R}$ ' lines $(15.12 \%)$ than ' $A$ ' lines $(14.3 \%)$.

Similarly, the PIC values in ' $A$ ' lines ranged from 0.1780 (ASSR108) to 0.5786 (ASSR5) with an average of 0.3062 per marker (Table $2)$. In case of ' $R$ ' lines, the PIC values varied from 0.1046 (ASSR9) to 0.5786 (ASSR108) with an average of 0.3614 per marker (Table 2). Surprisingly, the SSR Marker ASSR 108, which provided lowest PCI value of 0.1780 for ' $A$ ' lines also provided the highest PCI value of 0.5786 for ' $R$ ' lines (Table 2). Thus, the SSR marker ASSR108 could be more useful in studying diversity among ' $R$ ' lines than 'A' lines. However, other 6 markers, namely ASSR5, ASSR15, ASSR17, ASSR93, ASSR229 and ASSR236 showed PCI value $>0.500$ (Table 2). Thus, indicating possible usefulness of these markers in diversity studies among ' $A$ ', ' $B$ ' and ' $R$ ' lines in pigeonpea. Petchiammal et al., (2015) reported PIC value range from 0.071(CcM1602) to 0.787 (CcM2977) with an average PIC value of 0.147 for 40 SSR markers among 28 'A', 'B' and pollen parental lines. While, Odeny et al., (2007) and Saxena et al., (2010c) reported PIC values of 0.39 and 0.43 , respectively.

The relationship among ' $A$ ', 'B' and ' $R$ ' lines was deduced by cluster analysis using similarity matrix data of polymorphic SSR markers. The generated dendrogram clearly showed that genotypes fell broadly into two 
major clusters, namely 'A' and 'B' (Figure 2). Seven restores (ICPR2673, ICPR2740, ICPR2671, ICPR3472, ICPR3461, ICPR3462 and ICPR3494) and two CMS lines (ICPA2043 and ICPA2047) of $\mathrm{A}_{4}$ cytoplasm system, and one restorer of $\mathrm{A}_{2}$ cytoplasm GTR9, were grouped in major cluster 'A' (Figure 2). Whereas, six restores (ICPR3359, ICPR3337, ICPR4013, ICPR2751, ICPR3381 and ICPR3341) of $\mathrm{A}_{4}$ cytoplasm system, and six CMS lines (MS01A, MS04A, MS010A, GT33A, GT288A and GT290A) and four restores (AKPR9, AKPR100, AKPR417 and GTR11) of $\mathrm{A}_{2}$ cytoplasm systems, were grouped in major cluster ' $\mathrm{B}$ '. However, one genotype ICPR3760 formed as out group member. The major clusters 'A' and ' $\mathrm{B}$ ' were further divided into four sub-major clusters (AI. AII, BI and BII), eight sub-clusters (AIa, AIb, BIa, BIb, AIIa, AIIb, BIIa and BIIb) (Figure 2). Grouping of genotypes was consistent with the genetic background of the lines as well as comparable to the factorial analysis.

The genetic dissimilarity of all test genotypes varied from 0.40 to 0.81 with a mean genetic dissimilarity of 0.60 (Figure 2). Among 'A' lines, the mean genetic dissimilarity was 0.57 with a range of 0.40 to 0.75 . Among ' $R$ ' lines, the mean genetic dissimilarity was 0.61 with a range of 0.41 to 0.81 . However, the genetic dissimilarity among 5 restorers of $\mathrm{A}_{2}$ cytoplasm varied from 0.52 (AKPR9 and AKPR100) to 0.81 (AKPR100 \& AKPR9 and GTR9) with mean genetic dissimilarity of 0.66 (Figure 2). In restorers of $\mathrm{A}_{4}$ cytoplasm, the genetic dissimilarity varied from 0.41 (ICPR3341 and ICPR3381) to 0.75 (ICPR3341, ICPR3494 and ICPR2751, ICPR3760) with mean genetic dissimilarity of 0.54 . This indicated that, the restorer lines of $\mathrm{A}_{2}$ cytoplasm sources were genetically more diverse than $\mathrm{A}_{2}$ cytoplasm sources. Earlier, Saxena et al., (2010c) reported genetic dissimilarity of 67\% (ICPA 2042 and ICPB
2042) to $94 \%$ (ICPA 2039 and ICPB 2039) with an average of $78 \%$ among 'A', 'B' and ' $\mathrm{R}$ ' lines, respectively. Whereas, Bohra et al., (2017) reported decadal trend of mean genetic diversity of Indian pigeonpea cultivars over 4 decades (1975-85 to 2005-15) in the range of 0.51 to 0.56 .

Besides, by factorial analysis, two dimensional scatter plot was generated based on genetic dissimilarity of test genotypes (Figure 3). The plot consisted of $\mathrm{X}$ axis and $\mathrm{Y}$ axis, based on which it was divided into four co-ordinates (Co-1, Co-2, Co-3, and Co-4). Genotypes grouped in cluster $\mathrm{A}$ in dendrogram analysis (Figure 2) clearly distributed among coordinate 1 \& 4 in factorial analysis (Figure 3). Whereas, genotypes grouped in cluster B in dendrogram analysis (Figure 2) distributed among coordinate $2 \& 3$ (Figure 3 ).

Few genotypes namely ICPR 2751, ICPR3381， ICPR3341 \& AKPR417 belonging to cluster $\mathrm{B}$ in dendrogram distributed to coordinate 1 in factorial analysis (Figure 3). Genotype ICPR 3760 found as outgroup member in dendrogram was grouped in coordinate 4 in factorial analysis (Figure 3). Dendrogram broadly divided genotypes in two clusters, which was further distinguished into four groups by factorial analysis. Interestingly, a close agreement was observed between the results arising from dendrogram and factorial analysis. Bohra et al., (2017) reported a similar kind of findings, in which results of structure and factorial analyses were in close agreement. Thus combination of dendrogram and factorial analysis will help to choose heterotic combinations of hybrid parents. Genotypes placed in coordinate 1 and coordinate 3; coordinate 2 and coordinate 4 are genetically highly distant each other, thus they may produce best hybrid combinations. 
Table.1 Details of hybrid parental lines of pigeonpea used in the current study

\begin{tabular}{|c|c|c|c|}
\hline $\begin{array}{l}\text { Sl. } \\
\text { No. }\end{array}$ & $\begin{array}{l}\text { Parental } \\
\text { lines }\end{array}$ & Sterile cytoplasm source & Source \\
\hline \multicolumn{4}{|c|}{ Group1 } \\
\hline 1 & GT33A & Cajanus scarabaeoides $\left(\mathrm{A}_{2}\right)$ & SKNAU, Dantewara, Gujarat, India \\
\hline 2 & GT288A & - do- & - do- \\
\hline 3 & GT290A & -do- & - do- \\
\hline 4 & MS01A & -do- & PDKVV, Akola, Maharastra, India \\
\hline 5 & MS04A & - do- & - do- \\
\hline 6 & MS010A & -do- & - do- \\
\hline 7 & ICPA2043 & Cajanus cajanifolius $\left(\mathrm{A}_{4}\right)$ & JNKVV, Jabalpur, Madhya Pradesh, India \\
\hline 8 & ICPA2047 & - do- & - do- \\
\hline \multicolumn{4}{|c|}{ Group2 } \\
\hline 9 & ICPB2043 & Cajanus cajanifolius $\left(\mathrm{A}_{4}\right)$ & JNKVV, Jabalpur, Madhya Pradesh, India \\
\hline 10 & ICPB2047 & -do- & -do- \\
\hline \multicolumn{4}{|c|}{ Group3 } \\
\hline 11 & AKPR9 & Cajanus scarabaeoides $\left(\mathrm{A}_{2}\right)$ & PDKVV, Akola, Maharastra, India \\
\hline 12 & AKPR100 & -do- & -do- \\
\hline 13 & AKPR417 & - do- & -do- \\
\hline 14 & GTR9 & -do- & SKNAU, Dantewara, Gujarat, India \\
\hline 15 & GTR11 & -do- & -do- \\
\hline 16 & ICPR2438 & Cajanus cajanifolius $\left(\mathrm{A}_{4}\right)$ & ICRISAT, Hyderabad, India \\
\hline 17 & ICPR2671 & -do- & JNKVV, Jabalpur, Madhya Pradesh, India \\
\hline 18 & ICPR2673 & -do- & - do- \\
\hline 19 & ICPR2740 & - do- & -do- \\
\hline 20 & ICPR2751 & -do- & -do- \\
\hline 21 & ICPR3337 & -do- & - do- \\
\hline 22 & ICPR3341 & -do- & -do- \\
\hline 23 & ICPR3359 & -do- & -do- \\
\hline 24 & ICPR3381 & -do- & -do- \\
\hline 25 & ICPR3461 & -do- & -do- \\
\hline 26 & ICPR3462 & -do- & -do- \\
\hline 27 & ICPR3472 & -do- & -do- \\
\hline 28 & ICPR3494 & -do- & -do- \\
\hline 29 & ICPR4013 & -do- & -do- \\
\hline
\end{tabular}

SKNAU: Sardarkrushinagar Nagar Agril. University, Dantewara, Gujarat, India; PDKVV: Dr. Panjabrao Deshmukh Krishi Vidyapeeth, Akola, Maharastra, India; JNKVV: Jawaharlal Nehru Krishi Vishwa Vidyalaya, Jabalpur, Madhya Pradesh, India; ICRISAT:International Crops Research Institute for the Semi-Arid Tropics, Hyderabad, India; Group1: Cytoplasmic male sterile lines (CMS lines/A-lines); Group2: Cytoplasmic male sterile maintainer lines (B-lines); Group3: Male fertility restorer lines (R lines). 
Table.2 Details of polymorphic EST-SSR markers detected among hybrid parental lines of pigeonpea.

\begin{tabular}{|c|c|c|c|c|c|c|c|}
\hline \multirow{2}{*}{$\begin{array}{l}\text { Sl. } \\
\text { No. }\end{array}$} & \multirow[t]{2}{*}{ Marker Id. } & \multirow[t]{2}{*}{ (SSR Motif)n } & \multirow{2}{*}{$\begin{array}{l}\text { Allele size } \\
\text { (bp) }\end{array}$} & \multirow{2}{*}{$\begin{array}{c}\text { No. of } \\
\text { Alleles } \\
\text { produced }\end{array}$} & \multicolumn{3}{|l|}{ PIC value } \\
\hline & & & & & A lines & $\mathbf{R}$ lines & Overall \\
\hline 1 & ASSR1 & $(\mathrm{GA}) 10$ & $100-120$ & 2 & 0.3047 & 0.2149 & 0.2755 \\
\hline 2 & ASSR3 & $(\mathrm{AGAAAG}) 5$ & $150-180$ & 3 & 0.3719 & 0.3623 & 0.3633 \\
\hline 3 & ASSR5 & $(\mathrm{AAATT}) 6$ & $120-145$ & 2 & 0.5786 & 0.4862 & 0.5198 \\
\hline 4 & ASSR8 & (AGA)9 & $140-160$ & 2 & 0.3750 & 0.2484 & 0.3301 \\
\hline 5 & ASSR9 & $(\mathrm{AGA}) 8$ & $140-150$ & 2 & 0.2859 & 0.1046 & 0.1780 \\
\hline 6 & ASSR12 & $(\mathrm{AACAC}) 6$ & $170-180$ & 2 & 0.3719 & 0.3524 & 0.3633 \\
\hline 7 & ASSR13 & (ATTAG)5 & $150-160$ & 3 & NP & 0.3047 & 0.2356 \\
\hline 8 & ASSR14 & (ATC)7 & $140-150$ & 3 & 0.5632 & 0.4303 & 0.4018 \\
\hline 9 & ASSR15 & $(\mathrm{CAA}) 8$ & $120-150$ & 2 & 0.3047 & 0.5280 & 0.5674 \\
\hline 10 & ASSR16 & $(\mathrm{GTT}) 9$ & $160-170$ & 2 & 0.2149 & 0.3648 & 0.2533 \\
\hline 11 & ASSR17 & (ССТTCT)6 & $175-210$ & 4 & 0.3698 & 0.2188 & 0.5815 \\
\hline 12 & ASSR19 & (TGTTCA)5 & $160-170$ & 2 & 0.2149 & 0.3648 & 0.2533 \\
\hline 13 & ASSR20 & (AT) 11 & $130-140$ & 3 & 0.3589 & 0.4415 & 0.4226 \\
\hline 14 & ASSR23 & $($ CCTTCT) 5 & $130-150$ & 2 & 0.3047 & 0.1780 & 0.2149 \\
\hline 15 & ASSR38 & (CATTGC)7 & $100-120$ & 2 & 0.3750 & 0.3524 & 0.3707 \\
\hline 16 & ASSR42 & (GTT)8 & $150-155$ & 2 & NP & 0.3648 & 0.3197 \\
\hline 17 & ASSR43 & (CT) 12 & $105-120$ & 2 & 0.2149 & 0.3571 & 0.3750 \\
\hline 18 & ASSR48 & (AAGAGG)6 & $100-120$ & 2 & 0.3047 & 0.3589 & 0.3735 \\
\hline 19 & ASSR70 & (GGTAGA)6 & $130-180$ & 3 & 0.0000 & 0.4728 & 0.3298 \\
\hline 20 & ASSR93 & (CATTTG) 5 & $120-180$ & 3 & 0.5112 & 0.5243 & 0.5219 \\
\hline 21 & ASSR97 & (ATGGAC)8 & $300-320$ & 2 & 0.3750 & 0.3719 & 0.3729 \\
\hline 22 & ASSR99 & $(\mathrm{CAC}) 10$ & $150-155$ & 2 & NP & NP & 0.0644 \\
\hline 23 & ASSR100 & $(\mathrm{GGT}) 7$ & $130-160$ & 3 & 0.3402 & 0.5400 & 0.4562 \\
\hline 24 & ASSR108 & $(\mathrm{GAT}) 7$ & $170-220$ & 4 & 0.1780 & 0.5786 & 0.4427 \\
\hline 25 & ASSR109 & $(\mathrm{GAA}) 7$ & $130-140$ & 2 & 0.3047 & 0.3750 & 0.3698 \\
\hline 26 & ASSR120 & $(\mathrm{CTT}) 7$ & $170-190$ & 2 & 0.1948 & 0.3538 & 0.3498 \\
\hline 27 & ASSR146 & (CACCAT)6 & $180-200$ & 2 & 0.3750 & 0.3648 & 0.3729 \\
\hline 28 & ASSR148 & $(\mathrm{CAA}) 7$ & $180-190$ & 2 & 0.2149 & 0.3457 & 0.3047 \\
\hline 29 & ASSR153 & $(\mathrm{GAG}) 8$ & $150-160$ & 2 & 0.3750 & 0.3719 & 0.3666 \\
\hline 30 & ASSR155 & (TGGACA)5 & $120-140$ & 2 & 0.3047 & 0.2484 & 0.3502 \\
\hline 31 & ASSR169 & $(\mathrm{TCA}) 7$ & $170-180$ & 2 & 0.2149 & 0.3290 & 0.3161 \\
\hline 32 & ASSR170 & $(\mathrm{CAT}) 9$ & $180-185$ & 2 & 0.2859 & 0.3388 & 0.2800 \\
\hline 33 & ASSR173 & $(\mathrm{GAT}) 8$ & $180-190$ & 2 & 0.2149 & 0.3457 & 0.3747 \\
\hline 34 & ASSR189 & $(\mathrm{GTT}) 8$ & $170-185$ & 2 & 0.2688 & 0.3318 & 0.2873 \\
\hline 35 & ASSR205 & (ATGAAG)11 & $160-180$ & 2 & 0.3719 & 0.1706 & 0.2800 \\
\hline 36 & ASSR206 & (GTAATA)6 & $170-180$ & 2 & 0.3249 & 0.2859 & 0.2920 \\
\hline 37 & ASSR221 & (TCG)8 & $180-185$ & 2 & 0.3047 & 0.3741 & 0.3719 \\
\hline 38 & ASSR229 & (TAAGGG)5 & $150-180$ & 3 & 0.5676 & 0.5435 & 0.5050 \\
\hline 39 & ASSR230 & $($ GAGCAT) 9 & $160-170$ & 2 & 0.2392 & 0.3457 & 0.3161 \\
\hline 40 & ASSR236 & (ACTAGC) 10 & $190-380$ & 3 & 0.5547 & 0.5827 & 0.5885 \\
\hline 41 & ASSR237 & (GGTGAA)7 & $180-220$ & 3 & 0.1948 & 0.4236 & 0.4735 \\
\hline 42 & ASSR247 & (CACCAA)6 & $180-190$ & 2 & 0.3750 & 0.2392 & 0.3103 \\
\hline 43 & ASSR258 & (CCATA) 5 & $280-290$ & 2 & 0.3457 & 0.3711 & 0.3735 \\
\hline 44 & ASSR259 & (TATG)5 & $180-185$ & 2 & 0.3698 & 0.3750 & 0.3750 \\
\hline 45 & ASSR273 & (CCAA)6 & $150-160$ & 2 & 0.2859 & 0.3687 & 0.3498 \\
\hline
\end{tabular}




\begin{tabular}{|c|c|c|c|c|c|c|c|c|}
\hline 46 & \multicolumn{2}{|c|}{ ASSR279 } & (ACAGGA)7 & $200-220$ & 2 & 0.3750 & 0.3457 & 0.3666 \\
\hline 47 & \multicolumn{2}{|c|}{ ASSR281 } & (CAAATG)6 & $200-240$ & 3 & 0.5048 & 0.4917 & 0.4670 \\
\hline 48 & \multicolumn{2}{|c|}{ ASSR286 } & (TGTTCA)5 & $550-555$ & 2 & 0.3249 & 0.3750 & 0.3687 \\
\hline 49 & \multicolumn{2}{|c|}{ ASSR293 } & (AGA)7 & $120-140$ & 2 & 0.3698 & 0.3687 & 0.3737 \\
\hline 50 & \multicolumn{2}{|c|}{ ASSR297 } & (GCCACC) 5 & $200-240$ & 2 & 0.3047 & 0.3750 & 0.3663 \\
\hline 51 & \multicolumn{2}{|c|}{ ASSR304 } & (GTT)7 & $150-155$ & 2 & 0.3457 & 0.3571 & 0.3675 \\
\hline 52 & \multicolumn{2}{|c|}{ ASSR317 } & (GAGCAT) 9 & $160-180$ & 2 & 0.3457 & 0.3719 & 0.3746 \\
\hline 53 & \multicolumn{2}{|c|}{ ASSR350 } & (CAT) & $150-160$ & 2 & 0.1948 & 0.3589 & 0.3353 \\
\hline 54 & \multicolumn{2}{|c|}{ ASSR362 } & $(\mathrm{AG}) 13$ & $100-120$ & 2 & NP & 0.1780 & 0.2078 \\
\hline 55 & \multicolumn{2}{|c|}{ ASSR366 } & (CGT)8 & $140-150$ & 2 & 0.3457 & 0.3741 & 0.3719 \\
\hline 56 & \multicolumn{2}{|c|}{ ASSR372 } & (CACCAT) & $130-180$ & 3 & 0.4918 & 0.3814 & 0.3829 \\
\hline 57 & \multicolumn{2}{|c|}{ ASSR379 } & (TTCATG)6 & $150-160$ & 2 & 0.2859 & 0.3207 & 0.3737 \\
\hline 58 & \multicolumn{2}{|c|}{ ASSR380 } & (TTTC) 5 & $180-190$ & 2 & 0.3589 & 0.3524 & 0.3576 \\
\hline 59 & \multicolumn{2}{|c|}{ ASSR381 } & $(\mathrm{GAT}) 8$ & $150-180$ & 2 & 0.1948 & 0.2772 & 0.2447 \\
\hline 60 & \multicolumn{2}{|c|}{ ASSR383 } & (GAT)7 & $170-180$ & 2 & 0.3249 & 0.3741 & 0.3690 \\
\hline \multicolumn{3}{|c|}{ Total } & & \multicolumn{2}{|l|}{136} & & & \\
\hline Mea & & & & 2.26 & & & & \\
\hline $\begin{array}{l}\text { Max } \\
\text { allele }\end{array}$ & num & & 17 \&ASSR108 & 4 & & & & \\
\hline Ma & $\begin{array}{l}\text { ximum } \\
\text { IC }\end{array}$ & & & & 0.5786(ASSR5) & $\begin{array}{c}0.5786 \\
\text { (ASSR108) }\end{array}$ & 0.58 & (ASSR236) \\
\hline & $\begin{array}{l}\text { iimum } \\
\text { PIC }\end{array}$ & & & & 0.1780(ASSR108) & 0.1046 (ASSR9) & 0.17 & (ASSR9) \\
\hline & Iean & & & & 0.3062 & 0.3614 & 0.35 & \\
\hline
\end{tabular}

NP: Non-polymorphic marker

Fig.1 Polymorphism produced by EST- SSR markers ASSR229 and ASSR236 among different male sterile and restorer lines

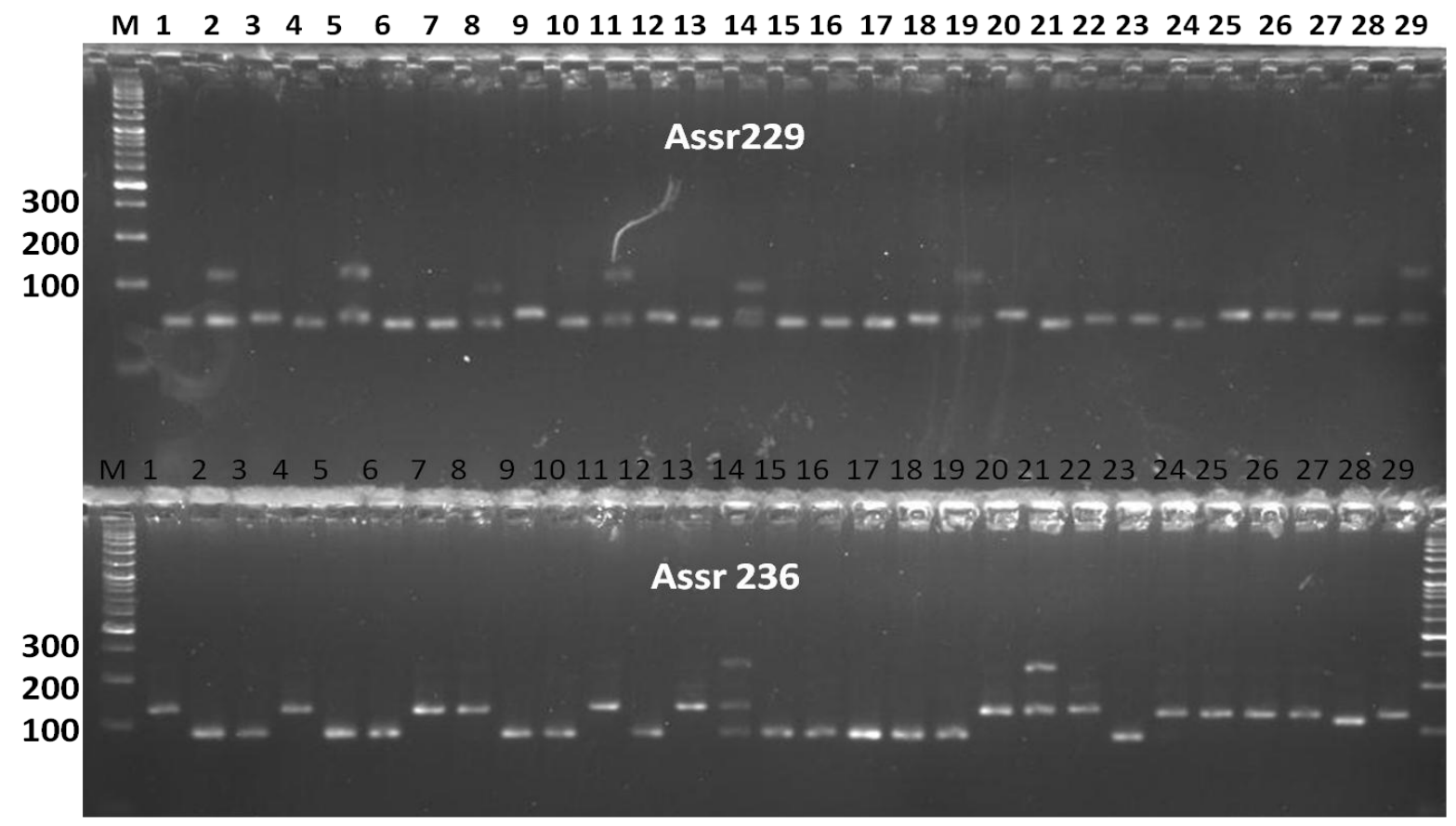

M - marker, 1 to 6 - $R$ lines, 7-10 - A\&B lines, 11-23 $R$ lines and 24 to 29 - A lines 
Fig.2 Dendrogram of A, B and R lines based on SSR markers using UPGMA cluster analysis

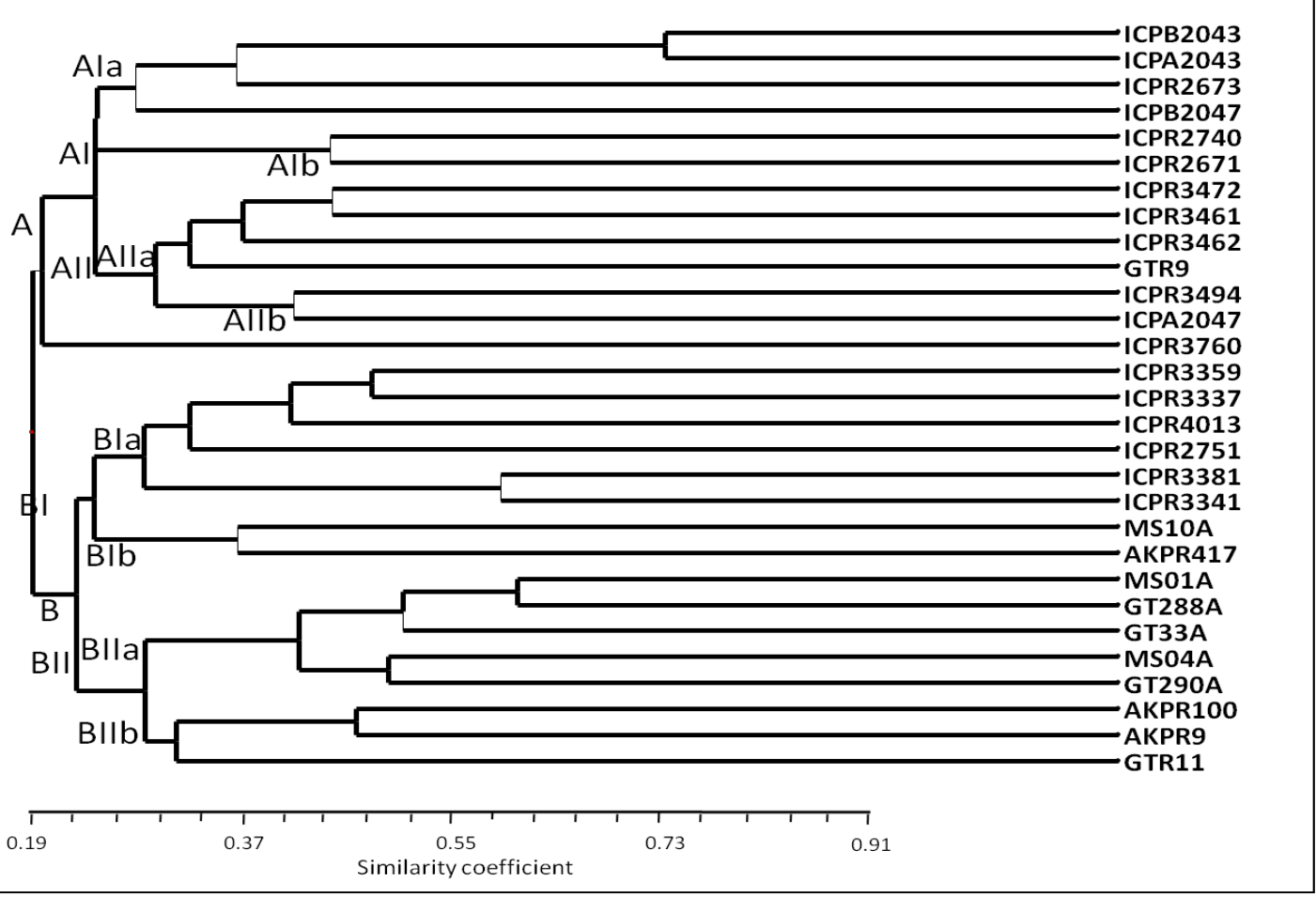

Fig.3 Factorial analysis of A, B and R lines of pigeonpea using DARWIN V5.0.128 software

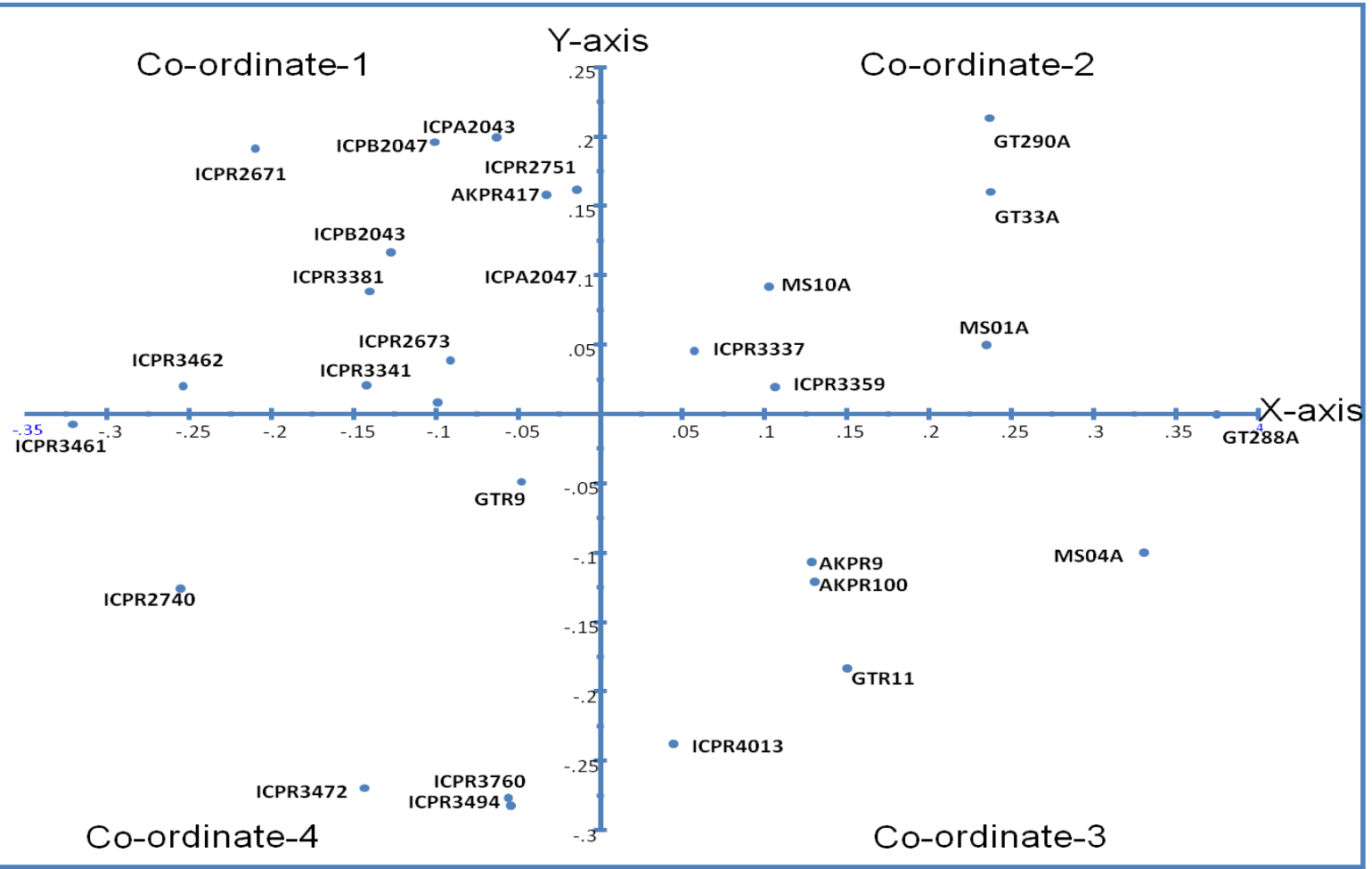


Present study revealed that ' $R$ ' lines of $A_{4}$ cytoplasm were genetically close to each other and also to 'A' lines except the ' $R$ ' line ICPR4013 (placed in coordinate 3). Thus the parental combinations by using the ' $R$ ' line ICPR4013 with two 'A' lines, ICPA2047 and ICPA2043 may produce best hybrids in $\mathrm{A}_{4}$ cytoplasm. Similarly in $A_{2}$ cytoplasm, 'R' line GTR9 (placed in coordinate 4) was genetically highly distant from both ' $R$ ' lines and ' $A$ ' lines, as rest of the ' $R$ ' lines and ' $A$ ' lines were placed in coordinates $2 \& 3$. Thus parental combination by using ' $R$ ' line GTR9 with ' $A$ ' lines of $A_{2}$ cytoplasm (placed in coordinate 2) may produce best hybrid combinations. The best heterotic combinations identified in present study are ICPA2047 X ICPR4013; ICPA2043 X ICPR4013 for A 4 cytoplasm, and GT290A X GTR9, GT33A X GTR9, MS01A X GTR 9, MS10A X GTR9 in $A_{2}$ cytoplasm. These genetically diverse combinations can be effectively used as candidate parental genotypes in hybrid development programme.

\section{References}

Anderson, J.R and Lubberstedt, T. 2003. Functional markers in plants. Trends Plant Science. 8: 554-560.

Ariyanayagam, R.P., Rao, A.N. and Zaveri, P.P. 1995. Cytoplasmic-genic male-sterility in interspecific matings of Cajanus. Crop Science. 35: 981-985.

Barbosa, A.M.M., Geraldi, I.O., Benchimol, L.L., Garcia, A.A.F., Souza, C.L. Jr, Souza, A.P. 2003. Relationship of intraand inter-population tropical maize single cross hybrid performance and genetic distances computed from AFLP and SSR markers. Euphytica. 130: 87-99.

Bohra, A., Jha, R., Pandey, G., Patil, P.G., Saxena, R.K., Singh, I.P., Singh, D., Mishra, R.K., Mishra, A., Singh, F., Varshney, R.K and Singh, N.P. 2017. New Hypervariable SSR Markers for Diversity Analysis, Hybrid Purity Testing and Trait
Mapping in Pigeonpea [Cajanus cajan (L.) Millspaugh]. Frontiers in Plant Science. 8: 377.

Burns MJ, Edwards KJ, Newbury HJ, FordLloyd BR and Baggot CD (2001) Development of simple sequence repeat (SSR) markers for the assessment of gene flow and genetic diversity in pigeonpea (Cajanus cajan). Molecular Ecology Notes. 1: 283-285.

Dalvi, V.A., Saxena, K.B., Luo, R.H and Li, Y.R. 2010. An overview of male-sterility systems in pigeonpea [Cajanus cajan (L.) Millsp.]. Euphytica. 173: 397-407.

Dutta, S., Kumawat, G., Singh, B.P., Gupta, D.K., Singh, S., Dogra, V., Gaikwad, K., Sharma, T.R., Raje, R.S., Bandhopadhya, T.K., Datta, S., Singh, M.N., Fakrudin, B., Kulwal, P., Wanjari, K.B., Varshney, R.K., Cook, D.R and Singh, N.K. 2011. Development of genic-SSR markers by deep transcriptome sequencing in pigeonpea [Cajanus cajan (L.) Millspaugh]. BMC Plant Biology. 11: 17.

FAOSTAT. Available at http://www.fao.org. Accessed on November 5, 2014.

FAOSTAT. Available at http://www.fao.org. Accessed on August 25, 2016.

Jordan, D., Tao, Y., Godwin, I., Henzell, R., Cooper, M and McIntyre, C. 2003. Prediction of hybrid performance in grain sorghum using RFLP markers. Theoretical and Applied Genetics. 106: 559-567.

Kassa, M.T., Penmetsa, R.V., CarrasquillaGarcia, N., Sarma, B.K., Datta, S., Upadhyaya, H.D., Varshney, R.K., Wettberg, E.J.B and Cook, D.R. 2012. Genetic patterns of domestication in pigeonpea (Cajanus cajan (L.) Millsp.) and wild Cajanus relatives. PLOS ONE. 7: 39563.

Kudapa, H., Bharti, A.K., Cannon, S.B., Farmer, A.D., Mulaosmanovic, B., Kramer, R., Bohra, A., Weeks, N.T., Crow, J.A., Tuteja, R., Shah, T., Dutta, S., Gupta, D.K., Singh, A., Gaikwad, K., Sharma, T.R., May, G.D., Singh, N.K and Varshney, R.K. 2012. A comprehensive 
transcriptome assembly of pigeonpea(Cajanus cajan L.) using Sanger and second-generation sequencing plat forms. Molecular Plant. 5: 1020-1028.

Lanza, L.L.B., Souza, C.L. Jr, Ottoboni, L.M.M., Vieira, M.L.C and Souza, A.P. 1997. Genetic distance of inbred lines and prediction of maize single-cross performance using RAPD markers. Theoretical and Applied Genetics. 94: 1023-1030.

Mallikarjuna, N and Saxena, K.B. 2005. A new cytoplasmic-nuclear male-sterility system derived from cultivated pigeonpea cytoplasm. Euphytica. 142: 143-148.

Mallikarjuna, N., Jadhav, D and Reddy, P. 2006. Introgression of Cajanus platycarpus genome in to cultivated pigeonpea, C. cajan. Euphytica. 149: 161167.

Murray, M.G and Thompson, W.F. 1980. Rapid isolation of high molecular weight plant DNA. Nucleic Acid Research. 8: 43214325.

Nadimpalli, R.G., Jarret, J.L., Pathak, S.C and Kochert, G. 1993. Phylogenetic relationships of pigeonpea (Cajanus cajan) based on nuclear restriction fragment length polymorphism. Genome. 36: 216-223.

Njung'e, V., Deshpande, S., Siambi, M., Jones, R., Silim, S and De, Villiers, S. 2016. SSR genetic diversity assessment of popular pigeonpea varieties in Malawi reveals unique fingerprints. Electronic Journal of Biotechnology. 21: 65-71.

Odeny, D.A., Jayashree, B., Ferguson, M., Hoinsington, D., Crouch, J and Gebhardt, C. 2007. Development, characterization and utilization of microsatellite markers in pigeonpea. Plant Breeding. 126: 130-136.

Panguluri, S.K., Janaiah, K., Govil, J.N., Kumar, P.A and Sharma, P.C. 2006. AFLP fingerprinting in pigeonpea (Cajanus cajan (L.) Millsp.) and its wild relatives. Genetic Resources and Crop Evolution. 53: 523-531.

Perrier, X., Flori, A and Bonnot, F. 2003. Data analysis method. In Hamon P, Seguin M,
Perrier X, Glaszmann JC (eds). Genetic diversity of cultivated tropical plants. Enfield, Science Publishers, Montpellier, $\mathrm{p}$ 43-76.

Petchiammal, K.I., Muthiah, A.R and Jayamani, P. 2015. Molecular characterization of CGMS, Maintainer and inbred lines and diversity analysis in pigeonpea [ Cajanus cajan (L.) Millsp.]. Legume Research, 38: 734-741.

Ratnaparkhe, M.B., Gupta, V.S., Ven, Murthy, M.R and Ranjekar, P.K. 1995. Genetic finger printing of pigeonpea (Cajanus cajan (L.) Millsp) and its wild relatives using RAPD markers. Theoretical and Applied Genetics. 91: 893-898.

Saxena, K.B. 2013b. A novel source of CMS in pigeonpea derived from Cajanusreticulatus. Indian Journal of Genetics and Plant Breeding. 73: 259-263.

Saxena, K.B and Kumar, R.V. 2003. Development of a cytoplasmic-nuclear male-sterility system in pigeonpea using C. scarabaeoides (L.). Thouars. Indian Journal of Genetics and Plant Breeding. 63: 225-229.

Saxena, K.B., Chauhan, Y.S., Johansen, C and Singh, L. 1992. Recent developments in hybrid pigeonpea research. In: Proceeding of the National Symposium on New Frontiers in Pulses Research and Development. 10-12 November, 1989, Kanpur, India, p 58-69.

Saxena, K.B., Kumar, R.V., Srivastava, N and Shiying, B. 2005. A cytoplasmic- genic male-sterility system derived from a crosses between Cajanus cajanifolius and Cajanus cajan. Euphytica. 145: 291-296.

Saxena, K.B., Kumar, R.V., Tikle, A.N., Saxena, M.K., Gautam, V.S., Rao, S.K., Khare, D.K., Chauhan, Y. S., Saxena, R.K., Reddy, B.V.S., Sharma, D., Reddy, L.J., Green, J.M., Faris, D.G., Mula, M., Sultana, R., Srivastava, R.K., Gowda, C.L.L., Sawargaonkar, S.L and Varshney, R.K. 2013. ICPH 2671 - the world's first commercial food legume hybrid. Plant Breeding. 132: 479-485.

Saxena, K.B., Singh, L and Gupta, M.D. 1990. 
Variation for natural out-crossing in pigeonpea. Euphytica. 46: 143-148.

Saxena, K.B., Sultana, R., Mallikarjuna, N., Saxena, R.K., Kumar, R.V., Sawargaonkar, S.L and Varshney, R.K. 2010a. Male-sterility systems in pigeonpea and their role in enhancing yield. Plant Breeding. 129: 125-134.

Saxena, R.K., Prathima, C., Saxena, K.B., Hoisinngton, D.A., Singh, N.K and Varshney, R.K. 2010b. Novel SSR markers for polymorphism detection in Pigeonpea (Cajanus spp.). Plant Breeding. 129: 142-148.

Saxena, R.K., Saxena, K.B and Varshney, R.K. 2010c. Application of SSR markers for molecular characterization of hybrid parents and purity assessment of ICPH 2438 hybrid of pigeonpea [Cajanus cajan (L.) Millspaugh]. Molecular Breeding. 26: 371-380.

Saxena, R.K., Saxena, K.B., Kumar, R.V., Hoisington, D.A and Varshney, R.K. 2010d. SSR-based diversity in elite pigeonpea genotypes for developing mapping populations to map resistance to Fusarium wilt and sterility mosaic disease. Plant Breeding. 129: 135-141.

Sheikh, W., Acharya, S., Patel, J.B., Kalaskar, S.R., Shinde, A.S and Patel, K.A. 2015.
Genetic fingerprinting of $\mathrm{A}$ and $\mathrm{R}$ lines of pigeonpea (Cajanus cajan (L.) Millsp.) using RAPD and SSR markers. Indian Journal of Biotechnology. 14: 328-333.

Souframanien, J., Manjaya, J.G., Krishna, T.G and Pawar, S.E. 2003. Random amplified polymorphic DNA analyses of cytoplasmic male sterile and male fertile pigeonpea (Cajanus cajan (L.) Millsp.). Euphytica. 129: 293-299

Wanjari, K.B., Patil, A.N., Manapure, P., Manjayya, J.G and Patel, M. 1999. Cytoplasmic male sterility in pigeonpea with cytoplasm from Cajanus volubilis. Annual Review of Plant Biology. 13: 170174.

Yang, S., Pang, W., Ash, G., Harper, J., Carling, J., Wenzl, P., Huttner, E., Zong, $X$ and Kilian, A. (2006). Low level of genetic diversity in cultivated pigeonpea compared to its wild relatives is revealed by diversity arrays technology. Theoretical and Applied Genetics. 113: 585-595.

Zhang, Q., Gao, Y.L., Yang, S.H., Ragab, R., Saghai-Maroof, M.A and Li, Z.B. 1994. A diallel analysis of heterosis in elite hybrid rice based on RFLPs and microsattelites. Theoretical and Applied Genetics. 89: 185-192.

\section{How to cite this article:}

Raghu, B.R., R.S. Raje, N.K. Singh, K.B. Saxena, D.A. Chauhan, S.A. Acharya, A.N. Patil, J.B. Patil, K.B. Wanzari and Khare, D. 2019. EST-SSR based Genetic Divergence and Prediction of Heterotic Combinations of Hybrid Parents in Pigeonpea. Int.J.Curr.Microbiol.App.Sci. 8(02): 2314-2325. doi: https://doi.org/10.20546/ijcmas.2019.802.270 